\title{
LA COLABORACIÓN PROCESAL COMO PRINCIPIO RECTOR DEL PROCEDIMIENTO DE FAMILIA
}

\author{
COLLABORATION AS A RULING PRINCIPLE \\ IN THE FAMILY PROCEDURAL LAW
}

\author{
MAITE AGUIRREZÁBAL GRÜNSTEIN* \\ Prof. de Derecho Procesal \\ Universidad de los Andes \\ Santiago - Chile
}

\section{RESUMEN}

Este trabajo analiza el principio de la colaboración en el proceso de familia, y sus diversas manifestaciones en la legislación chilena. La forma como se conducen los sujetos en el proceso ha sido una preocupación constante para la dogmática procesal, en diversos principios como el de la colaboración o cooperación procesal, entre otros. Junto con desarrollar algunas de las expresiones del este principio, se concluye que la cultura jurídico-procesal contemporánea entiende la necesidad de un juez cercano y con una intervención empática en el proceso con las partes y sus representantes.

Palabras clave: principio, colaboración, familia, proceso.

\section{ABSTRACT}

This paper analyzes the principle of collaboration in the family Chilean litigation procedure and its various manifestations in the Chilean law. The way in which the subjects are conducted in the process has been a constant concern for procedural dogmatics, in various principles such as procedural cooperation (collaboration), among others. Along with developing some of the expressions of this principle, it is concluded that the contemporary legalprocedural culture understands the need for a close judge with an empathic intervention in the process with the parties and their representatives.

Keywords: principle, collaboration, family, process.

\footnotetext{
* Profesora Investigadora de la Facultad de Derecho de la Universidad de los Andes, Monseñor Álvaro del Portillo N¹2.455, Las Condes, Santiago de Chile, correo electrónico: maguirrezabal@uandes.cl. Artículo recibido para evaluación el 27 de abril de 2018 y aceptado para su publicación el 28 de mayo de 2018.
} 


\section{INTRODUCCIÓN}

El acceso a la justicia y a la tutela judicial efectiva, consagrados a nivel constitucional, permiten que el ejercicio de la acción por parte del justiciable coloque en movimiento todo un aparato destinado a satisfacer sus necesidades legales.

La forma como se conducen los sujetos en el proceso ha sido una preocupación constante para la dogmática procesal, incorporándose bajo el alero del principio de la moralidad procesal, que a su vez se disgrega en diversos principios como el de la buena fe, la colaboración o cooperación procesal y la proscripción del abuso del proceso.

El postulado anterior encuentra su justificación en que nuestra actual sociedad exige solucionar los conflictos conforme a los hechos alegados y probados, como mecanismo para garantizar la defensa en juicio de los litigantes y el fin inmediato del proceso, es decir, la solución del conflicto por medio del descubrimiento de la verdad jurídica objetiva.

Sin perjuicio de lo ya señalado, el tema no es de fácil tratamiento, puesto que para su consagración la ley suele recurrir a enunciados abiertos con amplios márgenes interpretativos que se traducen en valoraciones éticas de la actividad de defensa. ${ }^{1}$

\section{FORMULACIÓN DEL PRINCIPIO DISPOSITIVO EN LA DOGMÁTICA PROCESAL CIVIL}

El principio dispositivo puede conceptuarse como aquel que en el proceso civil "atribuye a las partes la tarea de estimular la actividad judicial y aportar los materiales del proceso...”, ${ }^{2}$ y que les reconoce la iniciativa exclusiva para poner en movimiento el aparato jurisdiccional, permitiendo al ciudadano, sobre la base de un criterio de oportunidad, decidir si lleva a la tutela judicial el derecho subjetivo e interés legítimo del que cree ser titular.

\footnotetext{
${ }^{1}$ Se pronuncia en este sentido HunTER AMPUERo, Iván, “No hay buena fe sin interés: la buena fe procesal y los deberes de veracidad, completitud y colaboración”, Revista de Derecho de la Universidad Austral de Chile, Vol. XXI, N 2, Diciembre, 2008, pp. 151-182, AdRIÁN HEÑIN, Fernando, "El principio de moralidad en el proceso civil actual”, en Peyrano, J. (ed.), Principios Procesales, Rubinzal-Culzoni, Buenos Aires, 2011, T. I., pp. 739-763, y AnTorAz, Soledad, “Abuso procesal y principio de moralidad”, en Peyrano, J. (ed.), Principios Procesales, RubinzalCulzoni, Buenos Aires, 2011, T. II. pp. 17-47.

2 Montero, Juan; Ortells, Manuel; Gómez-Colomer, Juan, Derecho jurisdiccional. Parte general, Bosch Editores, Barcelona, 1993, T. I, pp. 465-471. En el mismo sentido, EsPARZA LEIBAR, Iñaki, El principio del debido proceso, Bosch Editores, Barcelona, 1995, p. 33.
} 
Palacio lo define como "aquel en cuya virtud se confía a la actividad de las partes tanto el estímulo de la función judicial como la aportación de materiales sobre los que ha de versar la decisión del juez", ${ }^{3}$ agregando Oteíza que el principio dispositivo supone "el dominio de la parte sobre el derecho que sustenta su pretensión". 4

Su vigencia obedece principalmente a la ideología liberal que imperaba en la época de la codificación a finales del siglo XIX y que se manifiesta en una desconfianza en los poderes del Estado, y en donde se considera que el proceso civil sirve principalmente para la discusión de intereses privados.

Tradicionalmente este principio, que se explica con la formula nemo iudex sine actore, ${ }^{5}$ confía a las partes el inicio del proceso civil y la aportación del material probatorio.

La doctrina alemana se encargó luego de limitar el concepto de principio dispositivo al de dominio por los litigantes del interés privado, distinguiéndolo así del principio de aportación de parte, relativo a la introducción de la prueba en el proceso, separación que ha sido acogida por doctrinas como la italiana y la española. ${ }^{6}$

Manresa, redactor de la Ley de Enjuiciamiento Civil española de 1881, refleja tal sentir, cuando expresa que "la mejor ley de procedimiento es la que deja menos campo al arbitrio judicial”, en la medida que este es "incompatible con las instituciones liberales", confundiendo el autor el dominio del objeto litigioso con el dominio respecto del proceso. ${ }^{7}$

\footnotetext{
${ }^{3}$ Palacio, Lino, Derecho procesal civil, Abeledo Perrot, Buenos Aires, 1979, pp. 253-254.

${ }^{4}$ OteizA, Eduardo, "El principio de colaboración y los hechos como objeto de la prueba. O 'probare o soccombere'. ¿Es posible plantear un dilema absoluto?”, en Morello, A. (coord.), Los hechos en el proceso civil, La Ley, Buenos Aires, 2003, pp. 83 y ss.

${ }^{5}$ Lo que significa que sólo habrá actividad jurisdiccional si hay un demandante.

${ }^{6}$ En este sentido, CAPPELLETTI, Mauro, "Le grandi tendenze evolutive del proceso civile nel diritto comparato”, en Cappelletti, Mauro, Processo e ideologie, Il Mulino, Bolonia, 1969, pp. 551 y ss.; Proto Pisani, Andrea, Lezioni di Diritto Processsuale Civile, Jovene, Roma, 2014. En lo que respecta a la dogmática española, entre otros, ARAgoneses Alonso, Pedro, Proceso y Derecho Procesal, Edersa, Madrid, 1997, p. 182-183; Gomez Orbaneja, Emilio, Derecho Procesal Civil, Civitas, Madrid, 1962, pp. 191 y ss., SERRA DomíngUEZ, Manuel, "Liberalización y socialización del proceso civil”, Revista de Derecho Procesal Iberoamericana, 1972, № 3, pp. 519 y ss.; CoRDóN Moreno, Faustino, Introducción al Derecho Procesal, Eunsa, Navarra, 1995, p. 140 y ss., y PICó I JunOY, Joan, El derecho a la prueba en el proceso civil, Bosch Editores, Barcelona, 1996, pp. 207 y ss.

${ }^{7}$ Manresa Navarro, José, Comentarios a la Ley de Enjuiciamiento Civil, Imprenta de la Revista de Legislación y Jurisprudencia, Madrid, 1881, T. I, p. 10, a lo que agrega MONTERo AROCA, Juan, Análisis crítico de la Ley de Enjuiciamiento Civil en su centenario, Civitas, Madrid, 1982, p. 80, que "la base ideológica liberal de los autores de la LEC les lleva a desconocer el reparto de funciones del juez y de las partes en el proceso, convirtiendo a aquél en un ente pasivo y a éstas en verdaderas dueñas de la Litis”.
} 
En sentido similar discurren Gómez Orbaneja y Herce Quemada, para quienes el principio dispositivo propiamente dicho "consiste en que las partes poseen dominio completo, tanto sobre su derecho sustantivo, como sobre los derechos procesales implícitos en el juicio, en el sentido que son libres de ejercitarlos o no". ${ }^{8}$

Agrega Wynes Millar que debería tratarse como un "principio de elección dispositiva", ${ }^{9}$ porque si las partes tienen el completo dominio de sus derechos en el proceso, también tienen la libertad para decidir el ejercicio de los mismos, y utilizar o no los medios procesales que la ley coloca a su disposición.

El principio dispositivo ha sido también caracterizado en un sentido formal y en sentido material. ${ }^{10}$ En la primera de sus manifestaciones, se refiere al manejo del proceso por parte de los interesados como instrumento técnico que garantiza el ejercicio de los derechos subjetivos que corresponderían a las partes en virtud del sentido material de este mismo principio, lo que les permitiría decidir sobre el ejercicio de la acción y los planteamientos que formulen al tribunal, pero dentro de las limitaciones formales establecidas por el proceso.

Como bien señala Calamandrei, es "la proyección en el campo procesal de aquella autonomía privada en los límites señalados por la ley, que encuentra su más enérgica afirmación en la tradicional figura del derecho subjetivo y, mientras la legislación substancial reconozca la autonomía, el principio dispositivo debe ser coherentemente mantenido en el proceso civil, como expresión insuprimible del poder reconocido a los particulares de disponer de su propia esfera jurídica”. ${ }^{11}$

En su orientación material, el principio dispositivo resulta de mayor aplicación cuando se trata de derechos subjetivos enteramente disponibles, disminuyendo su vigencia cuando se trata de derechos o intereses en donde se encuentran comprometidos derechos indisponibles o el interés general,

\footnotetext{
${ }^{8}$ Gómez Orbaneja, Emilio; Herce Quemada, Vicente, Derecho Procesal Civil, Civitas, Madrid, 1979, p. 191. Esta reflexión permite efectuar también la conocida distinción entre obligación y carga procesal, a partir de la cual el principio dispositivo tiene también un contenido de responsabilidad en su ejercicio.

${ }^{9}$ Wyness MillaR, Robert, Los principios formativos del procedimiento civil, Ediar, Buenos Aires, 1945, p. 65.

${ }^{10}$ CAPPELletti, Mauro, La testimonianza della parte nel sistema dell'oralità: contributo alla teoria della utilizzazione probatoria del sapere delle parti ne processo civile, Giuffre, Milano, 1974.

${ }^{11}$ Calamandrei, Piero, Instituciones de Derecho Procesal Civil, Ejea, Buenos Aires, 1981, vol. I, pp. 404-405.
} 
aumentando en dichas hipótesis el principio de actuación de oficio, no siendo en estos casos lícito para las partes limitar la actividad jurisdiccional. ${ }^{12}$

Una interpretación en extremo liberal del principio dispositivo podría llevarnos a concluir que las partes son dueñas del proceso y que pueden conducirlo a su arbitrio, olvidando que en el proceso interviene también el órgano jurisdiccional, no sólo como el llamado a solucionar el conflicto, sino también como un garante de la adecuada administración de justicia, controlando la actividad de las partes.

\section{LA COLABORACIÓN COMO PRINCIPIO PROCESAL}

El principio de colaboración procesal coloca al justiciable en un rol de cooperación con el servicio judicial que se traduce principalmente en la conducta procesal observada por las partes, y en virtud del cual se sancionan las actuaciones de quienes traicionan el ideal de la búsqueda en el éxito del proceso civil para que produzca los resultados esperados.

Se desarrolla a partir de una visión solidaria del proceso, que se asienta e implementa a partir de la buena fe y de la probidad, con la finalidad de afianzar el buen comportamiento en los intervinientes y el resultado útil de la jurisdicción.

La defensa de una parte no puede basarse en perjudicar el derecho a defensa de la otra o en la inducción a error del órgano jurisdiccional, ni su libertad puede extenderse al extremo de lesionar la buena fe y la ética procesal, puesto que "la colaboración, la buena fe y lealtad procesal, la moralización del proceso y el llamado solidarismo toman la palabra buscando dejar atrás la idea del proceso como una contienda entre partes parciales enfrentadas ante un tercero imparcial, y en el afán de la búsqueda de la verdad objetiva impone la redefinición del principio de la buena fe procesal para dar lugar a un deber de colaboración entre todos los que intervienen en el proceso, incluyendo deberes de asistencia del juez, y los deberes de veracidad e integridad de las partes". ${ }^{13}$

Así, la concepción del proceso como un conflicto de carácter adversarial, ha dado paso a una ideología menos conflictual y más colaborativa.

\footnotetext{
12 Couture, Eduardo, Fundamentos del derecho procesal civil, De Palma, Buenos Aires, 1958, p. 186. Sería el caso por ejemplo de los procesos relativos al estado civil de las personas o los procesos ante los tribunales de familia e incluso ante los tribunales del trabajo.

13 Palomo VÉlez, Diego, “Las cargas probatorias dinámicas: ¿es indispensable darse toda esta vuelta?”, Revista Ius et Praxis, 2013, año 19, № 2, p. 449. Cfr. también este sentido, CAPPELLETTI, cit. (n.6), p. 169.
} 
A lo largo de la historia, la relación entre la ética y el derecho procesal ha experimentado importantes cambios. Estas fluctuaciones no han sido indiferentes al espíritu de las concepciones ideológicas que han imperado en las distintas etapas históricas.

Durante el derecho romano clásico, especialmente en la etapa del derecho formulario, la buena fe asumió un papel fundamental en el curso del proceso judicial, ya que el pragmatismo romano no miró a la buena fe como principio general y abstracto que debía informar al ordenamiento procesal, sino más bien como un factor creador de derecho que imponía conductas particulares a los litigantes.

En la época medieval comenzó a operar una confusión paulatina entre la moral y el proceso que, lejos de conducir al mejoramiento de las relaciones de los sujetos procesales y al respeto cabal de los fines del proceso, se transformó en una fachada de justificación para restringir los derechos de las partes en litigio, atentando contra el ejercicio de su defensa.

En la actualidad, la óptica individualista de los derechos subjetivos que los concebía como ilimitados y absolutos, ha sido morigerada por la noción de bien social que cumplen y por la introducción de la teoría del abuso del derecho, que marca la moralidad en el ejercicio de los derechos subjetivos. ${ }^{14}$

La buena fe es un principio general que rige en todos los ámbitos del derecho. Sin embargo, no existe una definición única de este concepto, debiendo la doctrina definir los elementos que la componen.

Puede definirse como "aquella conducta exigible a toda persona, en el marco de un proceso, por ser socialmente admitida como correcta". ${ }^{15}$

Así, y tal como lo explica la definición anterior, la buena fe es un mecanismo que permite exigir ciertos deberes al deudor dentro del proceso y una conducta conforme a ella.

En el fondo, "con el principio de buena fe se busca que el proceso sea efectivamente un mecanismo para conseguir la justicia, evitando las posibles inmoralidades de que puedan servirse las partes en el ámbito procesal, para obtener una victoria a toda costa”. ${ }^{16}$

Busca conseguir que todos los que participan en una relación procesal ajusten sus actuaciones a las pautas éticas más elementales, reprobando

\footnotetext{
${ }^{14}$ En sentido contrario: Planiol, Marcel, Traité élémentaire de Droit Civil, Denoel, París, 1988, $6{ }^{a}$ ed., p. 280, quien sostuvo que hablar de abuso del derecho era una "logomaquia", esto es, una contradicción en las palabras, puesto que, para el autor, cuando hay abuso no hay derecho.

${ }^{15}$ Acosta, Hermógenes, “Proceso Civil y Constitución”, en Acosta, Hermógenes; Machado, José (coords.), Constitucionalización del Proceso Civil, Escuela Nacional de la Judicatura, Santo Domingo, 2005, p. 324.

${ }^{16}$ Picó I JunOY, Joan, El principio de la buena fe procesal, Bosch, Barcelona, 2003, p. 69.
} 
cualquier actuación que configure una utilización dolosa o fraudulenta del proceso.

El deber de colaboración, que constituye una especificación del principio de la lealtad procesal, puede definirse como "el conjunto de reglas de conducta, gobernadas por el imperativo ético, a las cuales deben ajustarse todos los sujetos del proceso...", que "proscribe la malicia, la mala fe y la deshonestidad como instrumentos inaceptables para ganar los pleitos", ${ }^{17}$ de manera que la veracidad y la probidad son parte integrante de este deber general.

Nuestro actual Código de Procedimiento Civil no consagra en forma expresa este principio, sino que éste se deduce implícitamente de algunas normas que sancionan la mala fe de las partes el artículo 88 o el artículo 280, ambos del texto legal ya citado y otras donde la idea de la buena o mala fe parece figurar implícita.

Sin perjuicio de lo señalado, parte de la doctrina considera que no es correcto establecer que en el proceso existan tales deberes u obligaciones, puesto que ambas nociones contrarían el espíritu dispositivo de los derechos de los que gozan las partes, diferenciándose los conceptos de carga, deber y obligación. ${ }^{18}$

\section{ALGUNAS EXPRESIONES DEL PRINCIPIO DE COOPERACIÓN EN EL PROCESO DE FAMILIA}

Hasta la dictación de la Ley 19.968 en el año 2004, los avances logrados en el plano de la adecuación de nuestra legislación de familia a los compromisos asumidos por nuestro país a nivel internacional se habían plasmado únicamente en el aspecto sustantivo y desde el punto de vista procesal, los avances no habían sido importantes. Esta falta de concordancia entre los aspectos sustantivos y los procesales restaba eficacia a los cambios y a las reformas.

La Comisión Nacional de la Familia identificó los obstáculos en el año 1993, al señalar que muchos de los problemas que se generan en el orden familiar apuntan al acceso a la justicia y abogaba por la creación de tribunales especializados, lo que finalmente se produjo en el año 2004.

17 Bustamante Rúa, Mónica, "Principios del Derecho Procesal”, en Ramírez Carvajal, D.; Bustamante Rúa, M.; Pabón Giraldo, L.; Rojas López, J.; Soto Soto, O.; Velásquez Restrepo, L., Derecho procesal contemporáneo, Universidad de Medellín, Medellín, 2010, p. 98.

${ }^{18}$ Couture, cit. (n. 12), pp. 171 y ss. 
La colaboración en un principio presente en la nueva legislación procesal de familia, y creemos que esta tendencia se observa en varias de las instituciones que consagra la Ley 19.968, como analizaremos a continuación.

\subsection{Relacionadas con la actuación de las partes}

1) En lo relativo al Abandono del Procedimiento

Establece el artículo 21 de la Ley 19.968 que "si llegado el día de la celebración de las audiencias fijadas, no concurriere ninguna de las partes que figuren en el proceso, y el demandante o solicitante no pidiere una nueva citación dentro de quinto día, el juez de familia procederá a declarar el abandono del procedimiento y ordenará el archivo de los antecedentes”.

La norma fija por lo tanto una sanción para la rebeldía de las partes, puesto que entiende que, si ninguna de ellas concurre a la audiencia, no poseen la voluntad de seguir con el procedimiento, ahorrando con ello costo y tiempo a la administración de justicia.

2) En lo que respecta al ofrecimiento de la prueba

El artículo 29 de la ley establece que las partes podrán ofrecer todos los medios de prueba de los que dispongan, pudiendo solicitar al juez de familia que ordene, además, la generación de otros de que tengan conocimiento y que no dependan de ellas, sino de un órgano o servicio público o de terceras personas, tales como pericias, documentos, certificaciones u otros medios aptos para producir fe sobre un hecho determinado.

La citada normativa establece un sistema amplio de libertad de medios probatorios, tendiente a que el órgano jurisdiccional obtenga la mayor cantidad de antecedentes para formar su convicción.

Así, las partes pueden ofrecer todos los medios probatorios lícitos de los que dispongan, pudiendo también solicitar al juez la generación de medios de prueba que dependan de terceros, lo que constituye un ejemplo entonces de la colaboración que, en general, terceros ajenos al proceso deben prestar para el adecuado desarrollo del mismo en lo que respecta a la aportación de la prueba.

Corresponde también a las partes la fiscalización del cumplimiento de los medios de prueba autorizados por el tribunal y solicitados a los terceros, por cuanto la norma establece que "tendrán plenas facultades para solicitar a los órganos, servicios públicos, o a terceras personas, la respuesta a los oficios solicitados en la audiencia preparatoria y que hayan sido admitidos 
por el tribunal, a fin de que puedan ser presentados como medios de prueba en la audiencia del juicio".

\section{3) En las convenciones probatorias}

Constituyen acuerdos celebrados por las partes para dar por acreditados ciertos hechos que luego no podrán ser discutidos, lo que tiende a disminuir el nivel de confrontación entre las mismas, ${ }^{19}$ pudiendo también el juez formular proposiciones a las partes sobre la materia, teniendo para ello a la vista las argumentaciones de hecho contenidas en la demanda y en la contestación.

4) En la suspensión condicional de la sentencia en materia de violencia intrafamiliar

Implica una forma colaborativa de superación del conflicto porque para que proceda se requiere junto con la aceptación de los hechos denunciados por el ofensor que se hayan establecido ciertas obligaciones de carácter familiar y de carácter reparatorio para con la víctima, habiendo además adquirido el compromiso de cumplir por un tiempo determinado una o más medidas cautelares, con lo que el término o solución del conflicto queda en definitiva entregado a las partes. ${ }^{20}$

Los efectos de la suspensión se encuentran regulados en el artículo 98 de la ley, que dispone que si transcurrido un año desde que se hubiese suspendido condicionalmente la dictación de la sentencia, el denunciado o demandado ha dado cumplimiento satisfactorio a las condiciones impuestas, el tribunal dictará una resolución declarando tal circunstancia, ordenará el archivo de los antecedentes y dispondrá la omisión en el certificado respectivo de la inscripción practicada, de conformidad con lo dispuesto en el inciso final del artículo 96.

En caso de incumplimiento del denunciado o demandado de las obligaciones acordadas en conformidad a la letra a) del inciso primero del

${ }^{19}$ Establece el Artículo 30 de la Ley 19.968 que “durante la audiencia preparatoria, las partes podrán solicitar, en conjunto, al juez de familia que dé por acreditados ciertos hechos, que no podrán ser discutidos en la audiencia de juicio”.

${ }^{20}$ Así lo dispone el Artículo 96, que permite al juez suspender condicionalmente la dictación de la sentencia, siempre y cuando se cumpla cualquiera de las siguientes condiciones:

a) Que se hayan establecido y aceptado por las partes obligaciones específicas y determinadas respecto de sus relaciones de familia y aquellas de carácter reparatorio a satisfacción de la víctima;

b) Que se haya adquirido por el demandado o denunciado, con el acuerdo de la víctima, el compromiso de observancia de una o más de las medidas cautelares previstas en esta ley por un lapso no inferior a seis meses ni superior a un año. 
artículo 96, el juez dictará sentencia y, atendida su naturaleza, decretará su ejecución.

Si el denunciado o demandado no cumpliere con alguna de las medidas impuestas en conformidad a la letra b) del mismo inciso, el tribunal establecerá tal hecho y dictará sentencia.

Puede también procederse a la revocación de la medida, "si la persona denunciada o demandada incurre en nuevos actos de violencia intrafamiliar en el período de condicionalidad”, caso en el cual se acumularán los antecedentes al nuevo proceso, debiendo el tribunal dictar sentencia conjuntamente respecto de ambos. ${ }^{21}$

\subsection{Relacionadas con la actuación de terceros}

1) En lo que respecta a la declaración testimonial

El artículo 33 de la ley dispone que los testigos tienen los deberes de comparecer y declarar, para todo aquel que no se encuentre legalmente exceptuado.

Tendrá la obligación de concurrir al llamamiento judicial practicado, de declarar la verdad sobre lo que se le pregunta y de no ocultar hechos, circunstancias o elementos acerca del contenido de su declaración, estableciendo las sanciones del artículo 240 del Código de Procedimiento Civil, $^{22}$ para aquel que se niegue a declarar sin justa causa.

El principio de colaboración procesal explica el deber de toda persona citada de comparecer ante el órgano jurisdiccional y declarar como testigo, constituyendo una carga pública del citado.

En el deber de colaboración radica también que el incumplimiento de los susodichos deberes le puede acarrear al testigo citado "la imposición de sanciones de índole procesal tales como multas y penales”, según acota Gozaíni. $^{23}$

Acertadamente consigna Devis Echandía que "se trata de un verdadero deber jurídico, porque existe coercibilidad para su cumplimiento mediante

\footnotetext{
${ }^{21}$ Artículo 99 de la Ley 19.968.

22 El artículo 240 del Código de Procedimiento Civil sanciona el desacato en los siguientes términos: "Cumplida una resolución, el tribunal tendrá facultad para decretar las medidas tendientes a dejar sin efecto todo lo que se haga en contravención a lo ejecutado. El que quebrante lo ordenado cumplir será sancionado con reclusión menor en su grado medio a máximo”.

${ }^{23}$ Gozaíni, Osvaldo, Tratado de Derecho Procesal Civil, La Ley, Buenos Aires, 2009, T. IV, p. 504.
} 
sanciones, puede emplearse la fuerza para obtener la comparecencia del testigo y su incumplimiento constituye un ilícito". ${ }^{24}$

Estas posiciones se enmarcan en la tesis defendida por Carnelutti y Calamandrei -en el sentido que existiría un verdadero Servicio Público Judicial que emplaza a todos los ciudadanos a ponerse a disposición de los órganos jurisdiccionales para colaborar con éstos en pos de una mejor prestación de justicia. ${ }^{25}$

2) En los informes requeridos a terceros

Relacionado también con la aportación del material probatorio, es procedente solicitar informes a terceros. Lo que interesa subrayar es que el tercero requerido de información soporta una carga pública y pesa sobre él un deber procesal que necesariamente encuentra explicación en el principio de cooperación procesal.

3) En la colaboración de terceros expertos: el Consejo Técnico

Atendida la competencia que la Ley 19.968 fija a los Tribunales de Familia, los transforma en tribunales especializados que requieren de una estructura multidisciplinaria.

El Consejo Técnico es un organismo auxiliar de la administración de justicia compuesto por profesionales en el número y con los requisitos que establece la ley, cuya función es asesorar, individual o colectivamente, a los jueces con competencia en asuntos de familia en el análisis y mejor comprensión de los asuntos sometidos a su conocimiento, en el ámbito de su especialidad.

En palabras de Henríquez, "El consejo técnico es un cuerpo, una estructura compuesta por consejeros técnicos, de carácter multidisciplinario, que actúan individual o conjuntamente, como auxiliares de la administración de justicia, liderado por un coordinador, asesorando a los jueces de familia, o bien gestionando la relación con actores relevantes de la red de intervención y apoyo psico-socio-jurídico y de salud en contacto con el Tribunal de Familia”, ${ }^{26}$ quien además, y en virtud de lo dispuesto por el artículo 457 del

\footnotetext{
${ }^{24}$ Devis Echandía, Hernando, Compendio de la Prueba Judicial, Rubinzal Culzoni, Santa Fe, 1984, T. II, p. 32.

${ }^{25}$ El aludido Servicio Público Judicial legitima el principio de cooperación procesal cuando se trata de justificar la colaboración forzada de terceros en un proceso civil que no los tiene como partes.

${ }^{26}$ Henríquez Galindo, Sergio, "El Consejo Técnico de los Tribunales de Familia de Chile. Regulación, límites y proyección”, Revista de Derecho Escuela de Postgrado de la Universidad de Chile, 2017, № 9, p. 136.
} 
Código Orgánico de Tribunales, poseen la calidad de auxiliares de la administración de justicia.

Según el artículo $5^{\circ}$ de la ley, posee como atribuciones el asistir a las audiencias de juicio a que sean citados para emitir las opiniones técnicas que le sean solicitadas; asesorar al juez para la adecuada comparecencia y declaración del niño, niña o adolescente; evaluar la pertinencia de derivar a mediación o aconsejar conciliación entre las partes y sugerir los términos en que ésta última pudiera llevarse a cabo y asesorar al juez en todas las materias relacionadas con su especialidad.

La incorporación que hace la Ley constituye una innovación positiva en función de conocer integralmente la problemática que atiende esta judicatura, ya que su asesoría especializada le permite al juez una mejor comprensión de los hechos y situaciones que se ventilan ante él, permitiéndole tener una visión interdisciplinaria indispensable para el pleno logro de los objetivos de la jurisdicción de familia.

La circunstancia que sean estos profesionales quienes soporten parte importante de la carga relacionada con el análisis de los antecedentes de los diversos asuntos que se le presentan, especialmente los vinculados a la amenaza o vulneración de derechos como en asuntos de violencia intrafamiliar, y que en virtud de lo mismo entreguen un conocimiento más acabado de los asuntos al tribunal, permite al juez enfocarse eficientemente en el análisis estricto del derecho. ${ }^{27}$

\subsection{Relacionadas con las facultades probatorias del juez y la dirección del proceso}

Por su parte, la ley profundiza en el rol del juez, tanto en la misión procesal, en la misión conciliadora, en la misión jurisdiccional y en la misión ejecutora, refiriéndose también a la justicia negociada y a los métodos alternos de resolución de conflictos.

1) En el control de admisibilidad de la demanda

El artículo 54 de la ley establece que uno o más jueces de los que componen el juzgado realizarán un control de admisibilidad de las demandas, denuncias y requerimientos que se presenten al tribunal.

Si en dicho control se advirtiese que la demanda presentada no cumple con los requisitos formales previstos en el artículo 57, el tribunal ordenará se

\footnotetext{
${ }^{27}$ Debe destacarse además su carácter multidisciplinario. El Acta 93-2005, en su Artículo Tercero prescribe que: "Los Juzgados de Familia propenderán a una integración multidisciplinaria de los consejos técnicos, procurando que su conformación incluya profesionales de diversas disciplinas”.
} 
subsanen sus defectos en el plazo que el mismo fije, bajo sanción de tenerla por no presentada.

Puede incluso rechazarla de plano, si estima que la presentación es manifiestamente improcedente, expresando los fundamentos de su decisión. ${ }^{28}$

2) En las facultades del juez para dirigir las audiencias

El artículo 26 dispone que el juez que preside la audiencia dirigirá el debate, ordenará la rendición de las pruebas y moderará la discusión.

Podrá impedir que las alegaciones se desvíen hacia aspectos no pertinentes o inadmisibles, pero sin coartar el ejercicio de los litigantes para defender sus respectivas posiciones.

También podrá limitar el tiempo de uso de la palabra a las partes que deban intervenir durante el juicio, fijando límites máximos igualitarios para todas ellas o interrumpiendo a quien haga uso manifiestamente abusivo de su facultad.

Además, ejercerá las facultades disciplinarias destinadas a mantener el orden y decoro durante el debate y, en general, a garantizar la eficaz realización del mismo. Quienes asistan a la audiencia no podrán adoptar un comportamiento intimidatorio, provocativo o contrario al decoro.

3) En el control de la actividad probatoria

La ley le reconoce al juez facultades para que, de oficio, pueda ordenar que se generen todos aquellos medios de prueba de que tome conocimiento o que, a su juicio, resulte necesario producir en atención al conflicto familiar de que se trate. ${ }^{29}$

El artículo 31 lo habilita también para que, de modo fundado, ordene que se excluyan de ser rendidas en el juicio aquellas pruebas que fueren manifiestamente impertinentes, tuvieren por objeto acreditar hechos públicos y notorios, resulten sobreabundantes o hayan sido obtenidas con infracción de garantías fundamentales.

4) En la adopción de medidas cautelares

La acentuación del carácter público del proceso se advierte con claridad en el proceso cautelar de familia sobre las personas, desde que, con arreglo a la norma contenida en el artículo 22 de la ley, el juez puede decretar de oficio las medidas cautelares innovativas o conservativas que estime

\footnotetext{
${ }^{28}$ Con excepción de los numerales 8) y 16) del artículo $8^{\circ}$, referidos a las acciones de filiación y a los actos de violencia intrafamiliar.

${ }^{29}$ Artículo 29 de la ley.
} 
procedentes, cuando concurran las circunstancias que ese mismo artículo señala. $^{30}$

En los procesos de familia las medidas cautelares adquieren un peculiar contorno, verificándose profundas modificaciones en punto a su carácter instrumental; a su determinación inaudita parte; a los presupuestos que hacen a su admisibilidad y ejecutabilidad y a la facultad del órgano para ordenarlas de oficio.

En este sentido, el órgano jurisdiccional posee amplias facultades para decretar medidas cautelares, especialmente si se trata de situaciones urgentes.

Así lo reconoce también el artículo 71 de la ley, en lo que respecta al procedimiento para la aplicación de medidas de protección de niños, niñas y adolescentes, cuando dispone que el juez podrá adoptar alguna de las medidas cautelares previstas en dicho artículo, "en cualquier momento del procedimiento, y aun antes de su inicio, de oficio, a solicitud de la autoridad pública o de cualquier persona, cuando ello sea necesario para proteger los derechos del niño, niña o adolescente”, y en el artículo 92 a propósito del procedimiento seguido por violencia intrafamiliar, en que se establece como un deber para el juez de familia "dar protección a la víctima y al grupo familiar".

\subsection{En la resolución alternativa de los conflictos}

El acceso a la justicia es hoy considerado como uno de los temas fundamentales del Derecho Procesal, y las reformas en nuestro país han ido orientándose en esa dirección.

La preocupación por hacer más accesibles los tribunales a los justiciables, y por mejorar los procedimientos que permitan garantizarles el ejercicio de sus derechos, ha llevado a analizar los obstáculos existentes y a plantearse una serie de cuestiones sobre cómo mejorar la tutela jurisdiccional.

\footnotetext{
${ }^{30}$ El artículo 22 contiene una norma general que faculta al juez para adoptar de oficio o a petición de parte en cualquier etapa del procedimiento o incluso antes de su inicio las medidas cautelares conservativas o innovativas que considere procedentes teniendo en cuenta la verosimilitud del peligro invocado y el peligro en la demora que implica la tramitación. Sólo podrán decretarse en casos urgentes y cuando así lo exija el interés superior del niño o la inminencia del daño que se trata de evitar. El legislador ha previsto un procedimiento de aplicación de medidas de protección de los derechos de los niños, niñas y adolescentes, con un conjunto de medidas especiales, contenidas en el artículo 71 de la ley. El mismo criterio ha seguido al momento de regular el procedimiento relativo a los actos de violencia intrafamiliar, que también contempla una tutela cautelar especial en protección de la víctima, en el artículo 92.
} 
El interés por el tema se ha enunciado mediante objetivos y métodos que promueven un cambio en la estructura clásica del sistema civil de resolución de conflictos.

Los mecanismos alternativos de solución de conflictos se inscriben en el contexto de las políticas sobre la mejora del acceso a la justicia, y representan una prioridad política para las instituciones a las que incumbe promover estas modalidades alternativas.

La posición mayoritaria de la doctrina es la de potenciar la utilización de la mediación y de las otras formas de resolución de conflictos que ayuden a evitar las molestias, las dilaciones y los costes que suponen las acciones judiciales, y de esta manera contribuir a que los ciudadanos puedan hacer valer sus derechos de un modo efectivo.

Una sociedad moderna no puede orientarse de forma monopólica a la acción de la justicia tradicional, sino que debe considerar las diversas posibilidades que se presentan para solucionar los conflictos intersubjetivos, y ver cuál puede resultar más adecuada para cada tipo de litigio.

Por ello, las alternativas al proceso civil no pueden significar un abandono de la modernización del sistema judicial, pues la eficacia de la administración de justicia sigue constituyendo uno de los pilares del sistema democrático.

Estos métodos alternativos, aunque suelen expresarse como una única categoría, presentan una diversidad de figuras tales como el arbitraje, la conciliación y la mediación, con una naturaleza y estructura organizativa distinta, según que la gestión de esos métodos se confíe a la iniciativa privada o a instituciones o entidades públicas.

\subsection{Clases de métodos alternativos previstos en la Ley 19.968}

El artículo 14 de la ley, ya reseñado, otorga prioridad fundamental a la colaboración procesal a través de la búsqueda de soluciones alternativas para el conflicto.

En este sentido, se han previsto procedimientos en los que un tercero ayuda a las partes a encontrar una solución mutuamente consentida, tales como la conciliación y mediación, en las que un tercero no toma una decisión sobre el conflicto, sino que interviene para que las partes encuentren ellas mismas la solución de mutuo acuerdo.

Son fórmulas de autocomposición que coinciden en la búsqueda de soluciones o acuerdos consensuales. 


\section{1) La mediación}

La mediación se caracteriza por la participación de un tercero que sin proponer ni imponer la solución busca el acercamiento entre las partes para que ellas acuerden esa solución. ${ }^{31}$

La esencia de la mediación la constituyen, sin duda, los principios sobre los que se está consolidando.

La importancia de los mismos es, pues, crucial, ya que se trata de los elementos que determinan el modo en que se configura la institución mediadora.

En efecto, en la legislación comparada, los principios son el eje en torno al cual gira la mediación, manteniéndose como estructura inalterable sobre la que construir el proceso en el que se desarrolla y los contratos que las partes suscriben en él.

De la trascendencia de dichos principios ya se hizo eco por ejemplo en la Recomendación $R$ (98) 1, sobre Mediación Familiar, aprobada por el Comité de Ministros del Consejo de Europa el 21 de enero de 1998.

Dicho instrumento legal puede considerarse como el referente inmediato de la regulación de la mediación en Europa, con honda trascendencia también en España, de ahí que haya sido reconocida expresamente como antecedente en las leyes de mediación familiar dictadas por las Comunidades Autónomas.

El valor que se le da a los principios de la mediación es notable, contemplándolos en relación con distintos aspectos de la misma.

Referente necesario en esta materia es, también, el Libro Verde sobre modalidades alternativas de solución de conflictos en el ámbito del derecho civil y mercantil, que tuvo en cuenta la citada R (98) 1, a pesar de ampliar el ámbito de intervención más allá de la mediación familiar.

El citado documento señala que se constata en la práctica por las autoridades públicas algunos principios comunes a todos los procedimientos, aunque los Estados miembros insisten especialmente en que se presentan en forma de garantías mínimas. Así, las partes en conflicto son libres de recurrir o no a las ADR, lo que afecta directamente al principio de voluntariedad, rigiéndose también el proceso por la imparcialidad y la equidad del tercero encargado del mismo, que ha de respetar el principio esencial de la confidencialidad.

\footnotetext{
31 Señala el artículo 103 que “para los efectos de esta ley, se entiende por mediación aquel sistema de resolución de conflictos en el que un tercero imparcial, sin poder decisorio, llamado mediador, ayuda a las partes a buscar por sí mismas una solución al conflicto y sus efectos, mediante acuerdos".
} 
La Ley 19.968 ha recogido también los principios reguladores del proceso de mediación, cuando en el artículo 105 sienta los principios informadores del proceso, entre los que destacan especialmente el de la voluntariedad, la igualdad y la confidencialidad.

\section{2) La conciliación}

En lo que respecta a la conciliación, la ley prioriza las oportunidades para que esta se produzca, otorgando al juez de familia diversas atribuciones en este sentido.

Así, se ha previsto que en la audiencia preparatoria el juez promueva la sujeción del conflicto a la mediación familiar a que se refiere el Título $\mathrm{V}$, suspendiéndose el procedimiento judicial y promover, por parte del tribunal, la conciliación total o parcial, conforme a las bases que éste proponga a las partes, ${ }^{32}$ a lo que se agrega la función del Consejo Técnico consistente en Evaluar, a requerimiento del juez, la pertinencia de derivar a mediación o aconsejar la conciliación entre las partes, sugiriendo los términos en que esta última pudiere llevarse a cabo. ${ }^{33}$

\section{CONCLUSIONES}

1. La cultura jurídico-procesal comparada contemporánea comienza a ser condicente en la necesidad de un juez cercano y con una intervención empática en el proceso con las partes y sus representantes que genera la necesidad de una transformación de paradigmas.

2. Ahora bien, la instauración del proceso por audiencias con la mejora de todas las condiciones orgánicas y financieras no parece ser suficiente sin fijar roles al juez y a las partes. Por el lado del juez se impone una visión que asume un rol activo y de conductor. De esta forma se verifica una simbiosis entre los sistemas adversarial e inquisitorio.

3. La competencia entre las partes por obtener un resultado positivo de victoria se matiza y equilibra con la cooperación impuesta en la conducción activa que debe desempeñar el juez, las conductas exigidas integran parámetros de trato equitativo, debido y justo proceso como valores internos. Estas son condiciones, no las únicas, aunque sí relevantes, de un proceso leal, justo, racional y eficiente.

\footnotetext{
${ }^{32}$ Artículo 61 de la Ley 19.968.

${ }^{33}$ Artículo $5^{\circ}$ de la Ley 19.968.
} 


\section{BIBLIOGRAFIA CITADA}

Acosta, Hermógenes, "Proceso Civil y Constitución”, en Acosta, Hermógenes; Machado, José (coords.), Constitucionalización del Proceso Civil, Escuela Nacional de la Judicatura, Santo Domingo, 2005.

ADRIÁN HEÑIN, Fernando, "El principio de moralidad en el proceso civil actual”, en Peyrano, Jorge W. (director), Principios Procesales, Rubinzal-Culzoni, Buenos Aires, 2011, T. I.

ANTORAZ, Soledad, "Abuso procesal y principio de moralidad. Recapitulación doctrinaria, jurisprudencial y normativa”, en Peyrano, Jorge W. (director), Principios Procesales, Rubinzal-Culzoni, Buenos Aires, 2011, T. II.

Aragoneses Alonso, Pedro, Proceso y Derecho Procesal, Edersa, Madrid, 1997.

Bustamante Rúa, Mónica, "Principios del Derecho Procesal", en Ramírez Carvajal, D.; Bustamante Rúa, M.; Pabón Giraldo, L.; Rojas López, J.; Soto Soto, O.; Velásquez Restrepo, L., Derecho procesal contemporáneo, Universidad de Medellín, Medellín, 2010.

Calamandrei, Piero, Instituciones de Derecho Procesal Civil, Ejea, Buenos Aires, 1981.

CAPPELLETTI, Mauro "Le grandi tendenze evolutive del proceso civile nel diritto comparato", en Cappelletti, M., Processo e ideologie, Il Mulino, Bolonia, 1969.

CAPPELletti, Mauro, La testimonianza della parte nel sistema dell'oralità: contributo alla teoria della utilizzazione probatoria del sapere delle parti ne processo civile, Giuffre, Milano, 1974.

CORDÓN MORENo, Faustino, Introducción al Derecho Procesal, Eunsa, Navarra, 1995.

COUTURE, Eduardo, Fundamentos del derecho procesal civil, De Palma, Buenos Aires, 1958.

Devis EchandíA, Hernando, Compendio de la Prueba Judicial, Rubinzal Culzoni, Santa Fe, 1984.

ESPARZA LEIBAR, Iñaki, El principio del debido proceso, Bosch Editores, Barcelona, 1995.

Gomez Orbaneja, Emilio, Derecho Procesal Civil, Civitas, Madrid, 1962.

Gómez Orbaneja, Emilio; Herce Quemada, Vicente, Derecho Procesal Civil, Civitas, Madrid, 1979. 
GozAínI, Osvaldo, Tratado de Derecho Procesal Civil, La Ley, Buenos Aires, 2009.

HenRíQuez Galindo, Sergio, "El Consejo Técnico de los Tribunales de Familia de Chile. Regulación, límites y proyección", en Revista de Derecho Escuela de Postgrado de la Universidad de Chile, 2017, № 9.

HunTER AMPUERO, Iván, "No hay buena fe sin interés: la buena fe procesal y los deberes de veracidad, completitud y colaboración”, Revista de Derecho Universidad Austral de Chile, 2008, Vol. XXI, Nº 2, pp. 151-182.

MANRESA NAVARRO, José, Comentarios a la Ley de Enjuiciamiento Civil, Imprenta de la Revista de Legislación y Jurisprudencia, Madrid, 1881.

Montero ArocA, Juan, Análisis crítico de la Ley de Enjuiciamiento Civil en su centenario, Civitas, Madrid, 1982.

MonTERO, Juan; OrTells, Manuel; GÓMEZ-Colomer, Juan, Derecho jurisdiccional. Parte general, Bosch Editores, Barcelona, 1993.

OTEIZA, Eduardo, "El principio de colaboración y los hechos como objeto de la prueba. O 'probare o soccombere'. ¿Es posible plantear un dilema absoluto?”, en Morello, A. (coord.), Los hechos en el proceso civil, La Ley, Buenos Aires, 2003.

Palacio, Lino, Derecho procesal civil, Abeledo Perrot, Buenos Aires, 1979.

PALOMO VÉLEZ, Diego, "Las cargas probatorias dinámicas: ¿Es indispensable darse toda esta vuelta?”, Revista Ius et Praxis, 2013, año 19, $\mathrm{N}^{\circ} 2$.

Planiol, Marcel, Traité élémentaire de Droit Civil, Denoel, París, 1988.

PICÓ Y JuNOY, Joan, El derecho a la prueba en el proceso civil, Bosch Editores, Barcelona, 1996.

PICÓ I JuNOY, Joan, El principio de la buena fe procesal, Bosch, Barcelona, 2003.

Proto Pisani, Andrea, Lezioni di Diritto Processuale Civile, Jovene, Roma, 2014.

SERRA Domínguez, Manuel, "Liberalización y socialización del proceso civil”, Revista de Derecho Procesal Iberoamericana, 1972, № 3.

WYNESS MILLAR, Robert, Los principios formativos del procedimiento civil, Ediar, Buenos Aires, 1945. 